\title{
The Benefits of Add-on Therapy of Vitamin D 5000 IU to the Vitamin D Levels and Symptoms in Diabetic Neuropathy Patients: A Randomized Clinical Trial
}

\author{
Rizaldy Taslim Pinzon (D) ${ }^{1,2}$ \\ Vincent Ongko Wijaya (D) \\ Vanessa Veronica (D' \\ 'Faculty of Medicine, Duta Wacana \\ Christian University, Yogyakarta, \\ Indonesia; '2Department of Neurology, \\ Bethesda Hospital, Yogyakarta, Indonesia
}

Background: Previous studies have demonstrated a significant relationship between vitamin D deficiency and the development of diabetic peripheral neuropathy (DPN). However, current studies are limited regarding the potential therapeutic benefits of vitamin D therapy in these patients.

Objective: This study aimed to assess the effect of oral vitamin D supplementation in patients with diabetic peripheral neuropathy in addition to standard treatment.

Methods: This study was a controlled, open-label, randomized clinical trial with an active comparator randomly allocated with a 1:1 ratio. The experimental group received an add-on oral vitamin D 5000 IU once daily and standard treatment (pregabalin, gabapentin, or amitriptyline) over eight weeks. The control group received standard treatment alone. The measured outcomes were the change in the score of the visual analog scale (VAS), numerical rating scale (NRS), and brief pain inventory (BPI). Vitamin D levels were also measured before and after the trial.

Results: Data from 68 subjects with DPN was collected and analyzed. Most of them $(60.3 \%)$ were female, aged $64.96 \pm 8.3$ years. After eight weeks of treatment, the experimental group showed a more significant reduction of mean VAS $(-3.34 \pm 2.03$ vs $-2.37 \pm$ $2.2, \mathrm{p}=0.044)$ and burning pain $(1.76 \pm 7.16$ vs $6.18 \pm 13.93, \mathrm{p}=0.046)$ scores compared to controls. Mood also improves better in the experimental group ( $88.2 \%$ vs $70.6 \%, \mathrm{p}=0.031)$. At the end of the study, vitamin $\mathrm{D}$ levels were also improved more significantly in the experimental group $(40.02 \pm 15.33 \mathrm{ng} / \mathrm{mL}$ vs $18.73 \pm 6.88 \mathrm{ng} / \mathrm{mL} ; \mathrm{p}<0.001)$ with greater changes from the baseline to week $8(+24.14 \pm 13.68 \mathrm{ng} / \mathrm{mL}$ vs $+3.10 \pm 4.20 \mathrm{ng} / \mathrm{mL} ; \mathrm{p}<0.001)$ compared to control group. The intervention group showed a negative correlation between vitamin $\mathrm{D}$ level and VAS score $(\mathrm{r}=-0.403, \mathrm{P}=0.018)$. There were no adverse events recorded in this study.

Conclusion: The addition of oral vitamin D 5000 IU to standard treatment significantly improves pain, mood, and vitamin D levels more effectively than standard treatment alone in patients with diabetic neuropathy.

Trial Registration: ClinicalTrials.gov.no NCT04689958.

Keywords: diabetic neuropathy, diabetes, vitamin D, supplementation

\section{Background}

Correspondence: Rizaldy Taslim Pinzon Duta Wacana Christian University School of Medicine, Doctor Wahidin

Sudirohusodo Street Number 5-25,

Yogyakarta, 55224, Indonesia

Email drpinzon17@gmail.com
Diabetic neuropathy is one of the microvascular complications of diabetes mellitus, with up to $30-50 \%$ incidences occurring in all diabetic patients. ${ }^{1}$ This complication is one of the primary causes of morbidity and mortality in 
diabetic patients, leading to a deterioration of their quality of life. ${ }^{1,2}$ A deficiency of vitamin D [25hydroxyvitamin $\mathrm{D}, 25(\mathrm{OH}) \mathrm{D}]$ is common in patients with diabetes, and low concentrations are associated with the presence and severity of sensory neuropathy

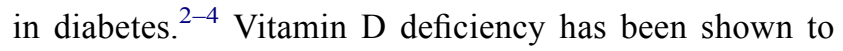
be an independent risk factor for diabetic peripheral neuropathy (DPN). ${ }^{2,4,5}$

Previous studies have reported a significant improvement of the symptoms and the pain of DPN using vitamin D supplementation. ${ }^{2,6-8}$ However, most studies lacked active comparator groups and utilized insufficient data at therapeutic doses to demonstrate the benefit of vitamin D supplementation on DPN symptoms. Vitamin $\mathrm{D}$ therapy is undergoing a limited number of clinical trials to determine its potential therapeutic benefits. In 51 individuals with type 2 diabetes and severe neuropathy, an open-label prospective trial found that taking 2000 IU of vitamin D daily for 3 months resulted in a $50 \%$ reduction in the visual analog scale (VAS). ${ }^{7}$ Similarly, a clinical trial indicated a significant improvement of neuropathy symptoms score in a group supplemented with oral vitamin D3 for eight weeks. The primary outcome was the improvement in the sensation of burning or hyperesthesia. ${ }^{2}$

Painful diabetic neuropathy is characterized by symptoms of pain, tingling, burning, and cramps in the lower legs and feet, significantly reducing the quality of life. $^{9-12}$ Recently, a previous study has shown a significant reduction in the severity of painful diabetic neuropathy after treatment with vitamin D. Vitamin D3 has been shown to reduce nerve demyelination and improve axonal regeneration. ${ }^{10,12}$ The current study assessed the benefits of oral vitamin D 5000 IU (Hi-D 5000) supplementation on patients with diabetic neuropathy.

\section{Methods}

\section{Study Design and Setting}

This study was a randomized clinical trial, open-label, controlled study with two study arms conducted at a large tertiary hospital in Yogyakarta, Indonesia. The study enrolment began in December 2020 and was completed in March 2021. The experimental group received an oral vitamin D 5000 IU (Hi-D 5000) once daily over eight weeks in addition to the standard treatment (pregabalin $1 \times 75 \mathrm{mg}$, gabapentin $1 \times 100 \mathrm{mg}$, or amitriptyline $1 \times 25 \mathrm{mg}$; the dose was adjusted according to each patients' symptom) for diabetic neuropathy. The control group received standard treatment only over the same period.

\section{Participants}

Participants were recruited consecutively from the pain clinic in our neurology department. Eligible participants were all patients with type 2 diabetes, aged $>18$ years, with a vitamin D status of $<30 \mathrm{ng} / \mathrm{mL}$ ) referred to the neurologist department to complain of diabetic peripheral neuropathy symptoms (ie, burning, tingling). All patients were assessed by a neurologist from history taking and physical examination. The exclusion criteria were subject to significant renal and liver impairment, subject to known hypersensitivity with vitamin D supplementation, pregnancy, breastfeeding patients, the patient enrolled in any clinical trial within a month, and unwillingness to join the study.

\section{Randomization and Blinding}

Following written informed consent, participants who fulfilled the criteria for the treatment phase of the study were allocated to 1 of 2 groups. Randomization was carried out using block randomization with a 1:1 ratio and assigned to the experimental $(n=34)$ or standard care $(n=34)$ trial group. A randomization list was generated by a statistician not involved with the study, using blocks of 5 stratifications. Complete blinding was considered difficult and not possible. Participants were informed of key elements of the respective intervention and follow-up they were randomized to, but not on information about the treatment and follow-up alternatives in the other group or the study's hypotheses.

\section{Ethical Consideration}

The authors confirm that all ongoing and related trials for this drug/intervention are registered. Ethical approval for the study was obtained from the Bethesda Hospital Ethics Committee with the number 120/KEPK-RSB/XII/20 and registered in the Indonesian Clinical Trial Registry with the number INA-MEODDY6 and ClinicalTrials.gov with the number of NCT04689958. All study participants gave signed informed consent in accordance with the Declaration of Helsinki. 


\section{Assessment}

Initially, we collected the general characteristics of all subjects: age, heights, weights, gender, marital status, education, occupation, health financing, duration of diabetes, comorbidity, comedication, the baseline score of NDS (Neuropathy Deficit Score), and NSS (Neuropathy Symptoms Score).

The primary outcome was the change from baseline in the score on the Visual Analog Scale (VAS), 0 to 10, with lower scores indicating lesser pain at a total of 8 weeks treatment duration, the Numerical Rating Scale (NRS), 0 to 100 , to assess different types of neuropathic pain including burning pain, electric shocks pain, tingling, and numbness with lower scores indicating lesser pain, as well as the percentage changes in the score on the Brief Pain Inventory (BPI), for pain impact on the interference on daily life including sleep quality, general activity, and mood. We measured the subjects BPI scores before and after the trial and categorized it into: vastly improved: $>50 \%$ improvement on their score; improved: $30-50 \%$ improvement on their score; slightly improved: $10-30 \%$ improvement on their score; no improvement: $<10 \%$ improvement on their score from the baseline. VAS and NRS scores will be examined three times for baseline, week-4, and week-8.

The secondary outcome included the change in vitamin D levels before and after the eight-week trial. Serum 25(OH)D was measured using an enzymelinked immunoassay (ELISA) method. We also measured the safety profile by monitoring any adverse events.

\section{Statistical Analysis}

Numerical data were reported as mean \pm Standard Deviation (SD), a categorical data were reported using frequency and percentage. The Chi-square test was used for categorical data. The independent $t$-test or MannWhitney test were used to compare the mean scores between the two groups. Paired $t$-test or Wilcoxon signedrank tests were also used to compare mean scores at baseline, week-4, and week-8 after intervention in each group. Spearman's rho correlation coefficients were calculated to define the linear association between Vitamin D level and pain changes (VAS). Statistical significance was set at $\mathrm{p}<0.05$, and SPSS version 23 was used for statistical analysis. Intention to treat analysis concept will be used for all the statistical analysis. Missing data will be imputed.

\section{Results}

Data from 68 subjects were collected and analyzed. A total of 68 subjects that fulfilled the inclusion and exclusion criteria were randomly assigned to the experimental and control groups, with each group consisting of 34 subjects. Due to being lost to follow-up, three subjects in the experimental group and one in the control group discontinued the study at the end of the follow-up period. (CONSORT flow chart of the study; Figure 1).

\section{Subjects' Baseline Characteristics}

Table 1 showed the baseline characteristics of the subjects. In this study, female subjects outnumbered male subjects, with $41(60.3 \%)$ female subjects and $27(39.7 \%)$ male subjects participating. The subjects in this study had a mean age of $64.96 \pm 8.3$ years. Diabetes has been present in study subjects for an average of $9.74 \pm 7.79$ years, with hypertension (58.8\%) being the most frequent comorbidity. Antihypertensive medications (60.3\%) were the most often used comedication by study subjects, followed by vitamin B (51.5\%), antiplatelet agents (44.1\%), and statins (19.1\%). The experimental group's mean baseline Neuropathy Deficit Score (NDS) and baseline Neuropathy Symptoms Score (NSS) scores were $4.15 \pm$ 0.93 and $2.12 \pm 1.01$, respectively, while the control group's mean baseline NDS and baseline NSS scores were $3.88 \pm 0.88$ and $2.5 \pm 0.99$, respectively. There was no significant difference in baseline characteristics and type of burn between the two groups, except for marital status.

\section{Pain Severity}

The Visual Analog Scale (VAS), 0-10, and the Numerical Rating Scale (NRS), 0-100, were used to assess pain severity in this study, as shown in Table 2 . The results showed on the baseline, the mean scores of VAS in the experimental and control groups before the intervention were $5.74 \pm 2.16$ and $5.46 \pm 2.13$, respectively. After eight weeks of treatment, the experimental group showed a more significant VAS score reduction than controls $(-3.34 \pm 2.03$ vs $-2.37 \pm 2.2, \mathrm{p}=0.044)$. In the burning type of pain outcome at week- 8 , the mean scores were significantly lower in the experimental 


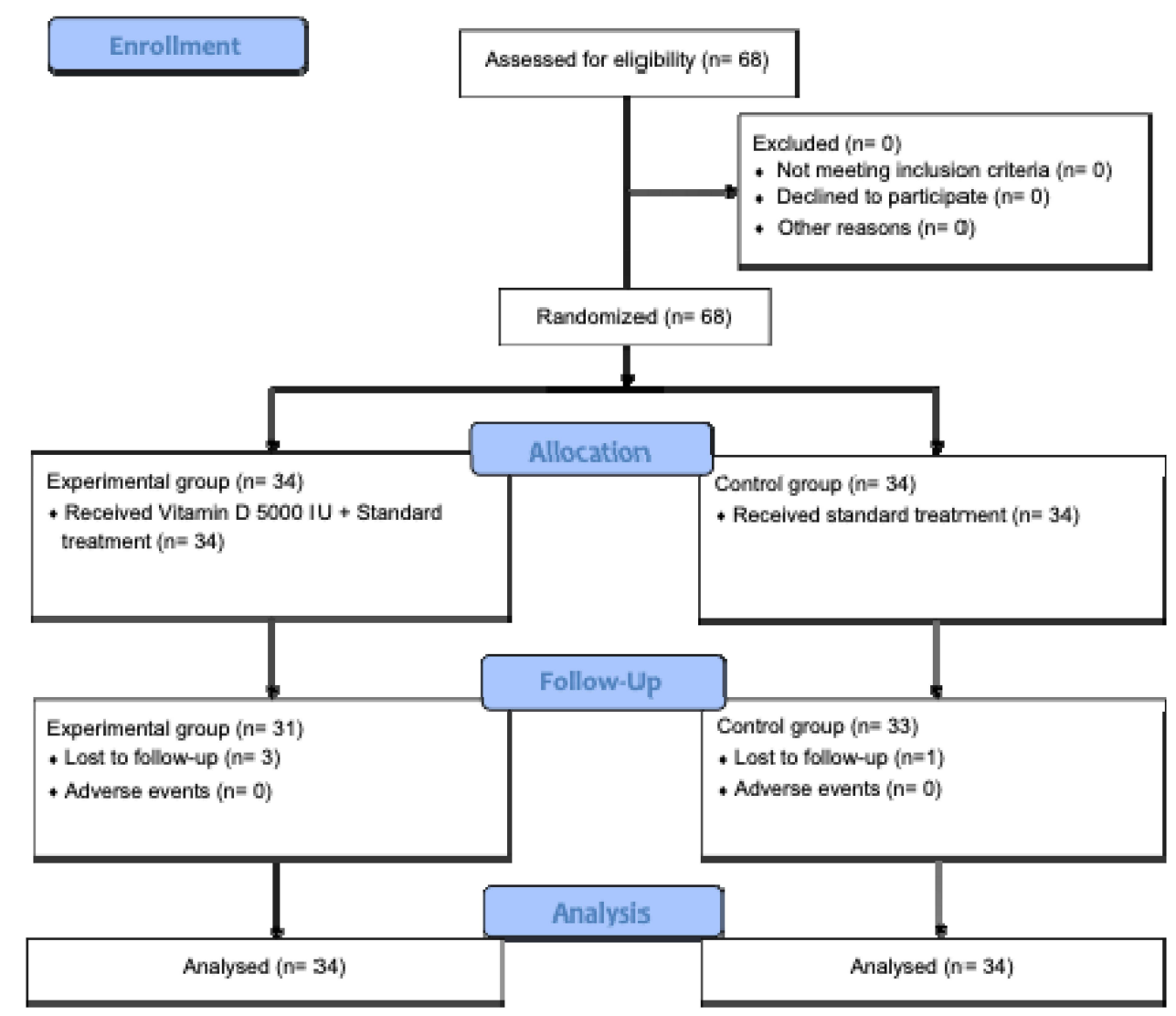

Figure I CONSORT flow chart of the study.

group compared to controls $(1.76 \pm 7.16$ vs $6.18 \pm$ 13.93, $\mathrm{p}=0.001)$. The results also showed that there was no significant difference in the severity of electric shocks pain $(\mathrm{p}=0.070)$, tingling $(\mathrm{p}=0.415)$, and numbness $(p=0.373)$ between the two groups on the change from baseline to week-8. The severity of VAS, burning pain, electric shocks pain, tingling, and numbness were measured three times during the study period. The score changes within-group for all types of pain were significantly different in both experimental and control groups $(\mathrm{p}<0.05)$.

While a negative correlation was found between vitamin D level and VAS score at week- 8 with Spearman's rho $(r=-0.403, P=0.018)$ [Figure 2] in the intervention group, no correlation was found in the control group $(P>0.05)$ [Figure 3].

\section{Sleep Quality, General Activity, and Mood} Figure 4 and Table 3 showed the impact of treatment on sleep quality, general activity, and mood measured at week 8 of the study. At week 8 , most of the study participants in the experimental group had experienced improvement (>30\% improvement on their score) in their sleep quality $(76.5 \%$ vs $73.5 \%)$, general activity $(88.2 \%$ vs $70.6 \%)$, and $\operatorname{mood}(88.2 \%$ vs $70.6 \%$ ) compared to controls. There were no significant differences in sleep quality $(\mathrm{p}=0.885)$ or general activity $(\mathrm{p}=0.096)$ between the experimental and control groups. However, there were significant differences in mood changes $(p=0.031)$ between the two groups.

\section{Vitamin D Levels}

Table 4 and Figure 5 represent the mean vitamin D levels from baseline to week 8 and a comparison of the experimental and control groups. Vitamin D levels increased significantly in both groups from baseline to week 8 , before and after the intervention $(\mathrm{p}<0.001)$. Between the experimental and control groups, there were significant differences in vitamin $\mathrm{D}$ levels in the experimental and control groups at week $8(40.02 \pm 15.33$ vs $18.73 \pm 6.88$; $\mathrm{p}<0.001$ ) as well as vitamin D levels' changes from 
Table I Baseline Characteristics

\begin{tabular}{|c|c|c|c|c|}
\hline & $\begin{array}{l}\text { Vitamin D } 5000 \text { IU + Standard } \\
\text { Treatment }(n=34)\end{array}$ & $\begin{array}{l}\text { Standard Treatment } \\
(n=34)\end{array}$ & Total $(n=68)$ & p-value \\
\hline Age, mean \pm SD (years) & $65.4 I \pm 8.5 I$ & $64.5 \pm 8.2$ & $64.96 \pm 8.3$ & 0.654 \\
\hline Heights, mean \pm SD (centimeters) & $157.24 \pm 9.42$ & $158.29 \pm 9.2$ & $157.76 \pm 9.25$ & $0.64 I$ \\
\hline Weights, mean \pm SD (kilograms) & $62.69 \pm 11.7$ & $65.5 \pm 7.36$ & $64.10 \pm 9.81$ & 0.241 \\
\hline \multicolumn{5}{|l|}{ Gender } \\
\hline Male & $12(35.3 \%)$ & $15(44.1 \%)$ & 27 (39.7\%) & 0.621 \\
\hline Female & $22(64.7 \%)$ & 19 (55.9\%) & $4 \mathrm{I}(60.3 \%)$ & \\
\hline \multicolumn{5}{|l|}{ Marital Status } \\
\hline Not Married & I (2.9\%) & I (2.9\%) & $2(2.9 \%)$ & $0.043^{*}$ \\
\hline Married & $25(73.5 \%)$ & $32(94.1 \%)$ & $57(83.8 \%)$ & \\
\hline Divorce & $8(23.5 \%)$ & I (2.9\%) & $9(13.2 \%)$ & \\
\hline \multicolumn{5}{|l|}{ Education } \\
\hline Elementary School & $3(8.8 \%)$ & $4(11.8 \%)$ & $7(10.3 \%)$ & 0.610 \\
\hline Junior High School & $4(11.8 \%)$ & I (2.9\%) & $5(7.4 \%)$ & \\
\hline Senior High School & $15(44.1 \%)$ & $16(47.1 \%)$ & $31(45.6 \%)$ & \\
\hline Bachelor Degree & $10(29.4 \%)$ & $9(26.5 \%)$ & $19(27.9 \%)$ & \\
\hline Others & $2(5.9 \%)$ & $4(1 \mathrm{l} .8 \%)$ & $6(8.8 \%)$ & \\
\hline \multicolumn{5}{|l|}{ Occupation } \\
\hline Domestic worker & I (2.9\%) & $2(5.9 \%)$ & $3(4.4 \%)$ & 0.639 \\
\hline Entepreneur & $3(8.8 \%)$ & $2(5.9 \%)$ & $5(7.4 \%)$ & \\
\hline Private Employee & $4(11.8 \%)$ & I (2.9\%) & $5(7.4 \%)$ & \\
\hline Unempolyemt & $3(8.8 \%)$ & $3(8.8 \%)$ & $6(8.8 \%)$ & \\
\hline Retired & $12(35.3 \%)$ & $17(50 \%)$ & $29(42.6 \%)$ & \\
\hline Others & II (32.4\%) & $9(26.5 \%)$ & $20(29.4 \%)$ & \\
\hline \multicolumn{5}{|l|}{ Type of Health Financing } \\
\hline Public insure & $28(82.4 \%)$ & $21(61.8 \%)$ & 49 (72.1\%) & 0.246 \\
\hline Private insure & $0(0 \%)$ & I (2.9\%) & $\mathrm{I}(\mathrm{I} .5 \%)$ & \\
\hline Company insure & I $(2.9 \%)$ & $3(8.8 \%)$ & $4(5.9 \%)$ & \\
\hline Others & $5(14.7 \%)$ & $9(26.5 \%)$ & $14(20.6 \%)$ & \\
\hline Duration of Diabetes, mean \pm SD (years) & $8.67 \pm 7.83$ & $10.82 \pm 7.7$ & $9.74 \pm 7.79$ & 0.160 \\
\hline \multicolumn{5}{|l|}{ Comorbidities } \\
\hline Hypertension & $18(52.9 \%)$ & $22(64.7 \%)$ & $40(58.8 \%)$ & 0.324 \\
\hline Cardiovascular disease & $15(44.1 \%)$ & 21 (6I.8\%) & $36(52.9 \%)$ & 0.145 \\
\hline Gastrointestinal disease & $2(5.9 \%)$ & 5 (14.7\%) & $7(10.3 \%)$ & 0.231 \\
\hline
\end{tabular}


Table I (Continued).

\begin{tabular}{|c|c|c|c|c|}
\hline & $\begin{array}{l}\text { Vitamin D } 5000 \text { IU + Standard } \\
\text { Treatment }(n=34)\end{array}$ & $\begin{array}{l}\text { Standard Treatment } \\
(n=34)\end{array}$ & Total $(n=68)$ & p-value \\
\hline \multicolumn{5}{|l|}{ Co-medications } \\
\hline Antihypertensive & 19 (55.9\%) & $22(64.7 \%)$ & $4 \mathrm{I}(60.3 \%)$ & 0.457 \\
\hline Vitamin B & $22(62.9 \%)$ & $13(38.2 \%)$ & $35(51.5 \%)$ & 0.051 \\
\hline Antiplatelet & $13(38.2 \%)$ & 17 (50\%) & $30(44.1 \%)$ & 0.329 \\
\hline Statin & $6(17.6 \%)$ & 7 (20.6\%) & $13(19.1 \%)$ & 0.758 \\
\hline Baseline NDS Scores, mean \pm SD & $4.15 \pm 0.93$ & $3.88 \pm 0.88$ & $4.01 \pm 0.91$ & 0.244 \\
\hline Baseline NSS Scores, mean \pm SD & $2.12 \pm 1.01$ & $2.5 \pm 0.99$ & $2.31 \pm 1.01$ & 0.097 \\
\hline
\end{tabular}

Notes: Data are presented as mean \pm standard deviation (SD) and $n(\%)$; ${ }^{*}$ - value is statistically significant.

Abbreviations: NDS, neuropathy deficit score; NSS, neuropathy symptoms score.

Table 2 Comparing the Mean Scores of Pain Severity Before and After the Intervention Between Both Groups

\begin{tabular}{|c|c|c|c|c|}
\hline & $\begin{array}{l}\text { Vitamin D } 5000 \mathrm{IU}+\text { Standard } \\
\text { Treatment }(n=34)\end{array}$ & $\begin{array}{l}\text { Standard Treatment } \\
(n=34)\end{array}$ & $\begin{array}{l}\text { Overall } \\
(n=68)\end{array}$ & p-value \\
\hline \multicolumn{5}{|l|}{ Visual analog scale $(0-10)$} \\
\hline Baseline & $5.74 \pm 2.16$ & $5.46 \pm 2.13$ & $5.60 \pm 2.13$ & 0.560 \\
\hline Week 4 & $3.76 \pm 2.32$ & $3.81 \pm 2.47$ & $3.79 \pm 2.38$ & 0.946 \\
\hline Week 8 & $2.39 \pm 2.09$ & $3.09 \pm 2.33$ & $2.74 \pm 2.22$ & 0.221 \\
\hline Changes from baseline to week 8 & $-3.34 \pm 2.03$ & $-2.37 \pm 2.2$ & $-2.85 \pm 2.16$ & $0.044^{*}$ \\
\hline$p$-value ${ }^{b}$ & $<0.00 I^{*}$ & $<0.00 I^{*}$ & $<0.00 I^{*}$ & \\
\hline \multicolumn{5}{|l|}{ Burning pain $(0-100)$} \\
\hline Baseline & $11.76 \pm 23.8$ & $17.06 \pm 25.88$ & $|4.4| \pm 24.82$ & 0.384 \\
\hline Week 4 & $4.18 \pm 11.84$ & $9.41 \pm 17.22$ & $6.76 \pm|4.9|$ & 0.189 \\
\hline Week 8 & $1.76 \pm 7.16$ & $6.18 \pm 13.93$ & $3.97 \pm 11.21$ & $0.046^{*}$ \\
\hline Changes from baseline to week 8 & $-10 \pm 20.15$ & $-10.89 \pm 25.5 \mid$ & $-10.44 \pm 22.82$ & 0.859 \\
\hline $\mathrm{p}$-value & $0.007^{*}$ & $0.023^{*}$ & $0.001 *$ & \\
\hline \multicolumn{5}{|l|}{ Electric shocks pain $(0-100)$} \\
\hline Baseline & $10.29 \pm 21.39$ & $22.35 \pm 27.64$ & $16.32 \pm 25.27$ & 0.057 \\
\hline Week 4 & $6.47 \pm 17.21$ & $12.35 \pm 20.75$ & $9.41 \pm 19.15$ & 0.110 \\
\hline Week 8 & $4.71 \pm 13.54$ & $6.76 \pm 13.64$ & $5.74 \pm 13.63$ & 0.482 \\
\hline Changes from baseline to week 8 & $-5.59 \pm 12.36$ & $-15.59 \pm 23.77$ & $-10.59 \pm 19.46$ & 0.070 \\
\hline$p$-value ${ }^{b}$ & $0.011 *$ & $0.001 *$ & $<0.00 I^{*}$ & \\
\hline
\end{tabular}


Table 2 (Continued).

\begin{tabular}{|c|c|c|c|c|}
\hline & $\begin{array}{l}\text { Vitamin D } 5000 \text { IU + Standard } \\
\text { Treatment }(n=34)\end{array}$ & $\begin{array}{l}\text { Standard Treatment } \\
(n=34)\end{array}$ & $\begin{array}{l}\text { Overall } \\
(n=68)\end{array}$ & p-value ${ }^{a}$ \\
\hline \multicolumn{5}{|l|}{ Tingling $(0-100)$} \\
\hline Baseline & $30.88 \pm 29.27$ & $36.18 \pm 30.85$ & $33.53 \pm 29.96$ & 0.483 \\
\hline Week 4 & $17.94 \pm 22.8$ & $25.29 \pm 27.55$ & $21.62 \pm 25.37$ & 0.242 \\
\hline Week 8 & $10.59 \pm 18.9$ & $20.29 \pm 26.91$ & $15.44 \pm 23.59$ & 0.096 \\
\hline Changes from baseline to week 8 & $-20.29 \pm 23.29$ & $-15.88 \pm 21.62$ & $-18.09 \pm 22.41$ & 0.415 \\
\hline$p$-value ${ }^{b}$ & $<0.00 I^{*}$ & $<0.00 I^{*}$ & $<0.001^{*}$ & \\
\hline \multicolumn{5}{|l|}{ Numbness $(0-100)$} \\
\hline Baseline & $43.53 \pm 31.13$ & $41.76 \pm 25.76$ & $42.65 \pm 28.37$ & 0.719 \\
\hline Week 4 & $29.41 \pm 29.23$ & $30.88 \pm 27.34$ & $30.15 \pm 27.34$ & 0.750 \\
\hline Week 8 & $20.59 \pm 25.93$ & $26.47 \pm 26.73$ & $23.53 \pm 26.30$ & 0.257 \\
\hline Changes from baseline to week 8 & $-22.94 \pm 24.93$ & $-15.29 \pm 18.13$ & $-19.12 \pm 21.97$ & 0.373 \\
\hline$p$-value ${ }^{b}$ & $<0.00 I^{*}$ & $<0.00 I^{*}$ & $<0.00 I^{*}$ & \\
\hline
\end{tabular}

Notes: Data are presented as mean \pm standard deviation (SD); ${ }^{\mathrm{a} C}$ Comparison between the experimental and control group; ${ }^{\mathrm{b}}$ Comparison within-group under the same conditions; *p-value is statistically significant.

baseline to week $8(+24.14 \pm 13.68$ vs $+3.10 \pm 4.20$; Discussion

$\mathrm{p}<0.001$ ), respectively.

Vitamin D [25-hydroxyvitamin D, 25(OH) D] deficiency is common in diabetic patients, and low levels have

\section{Adverse Events}

There were no adverse events reported in either the experimental or control groups in this study. been linked to the presence and severity of sensory neuropathy. ${ }^{2-4}$ A serum $25(\mathrm{OH})$ D level of less than $20 \mathrm{ng} / \mathrm{mL}$ is considered vitamin D deficiency, whereas

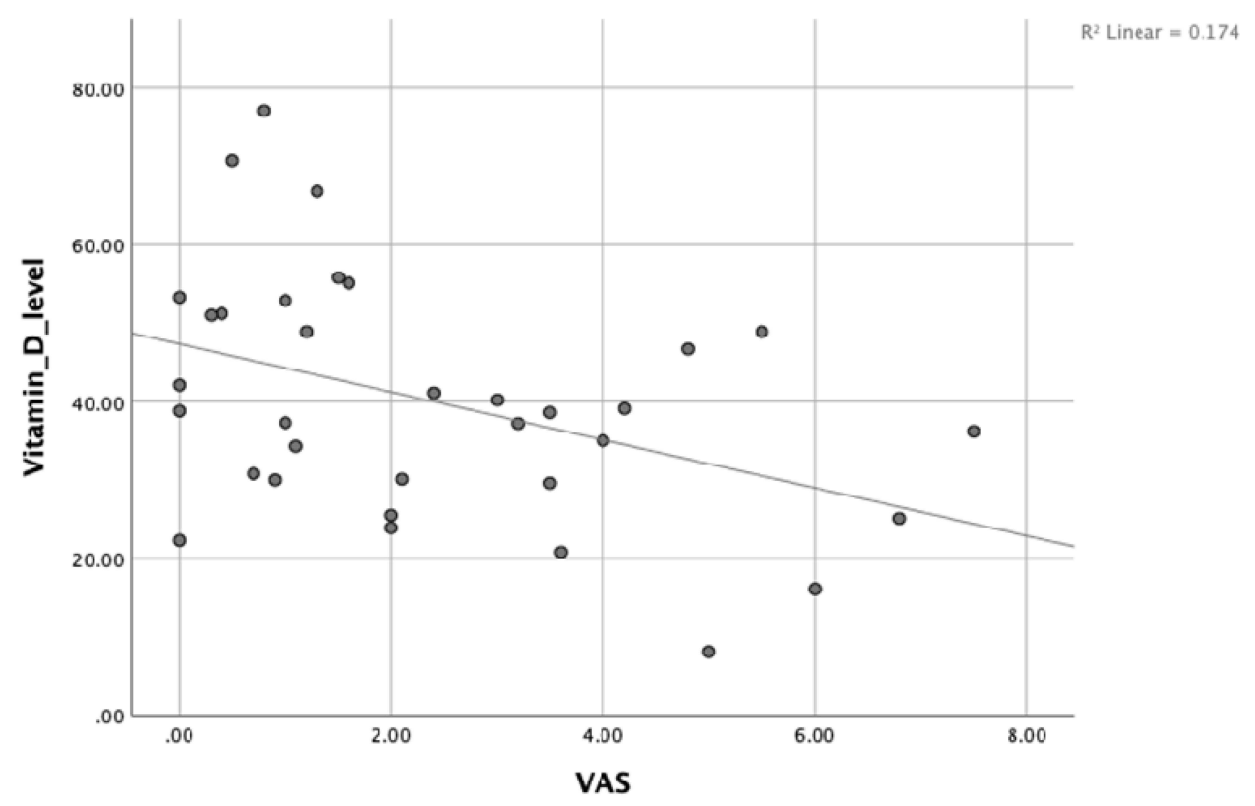

Figure 2 Correlation between vitamin D levels [serum $25(\mathrm{OH}) \mathrm{D}]$ and the VAS at week-8 in the experimental group. 


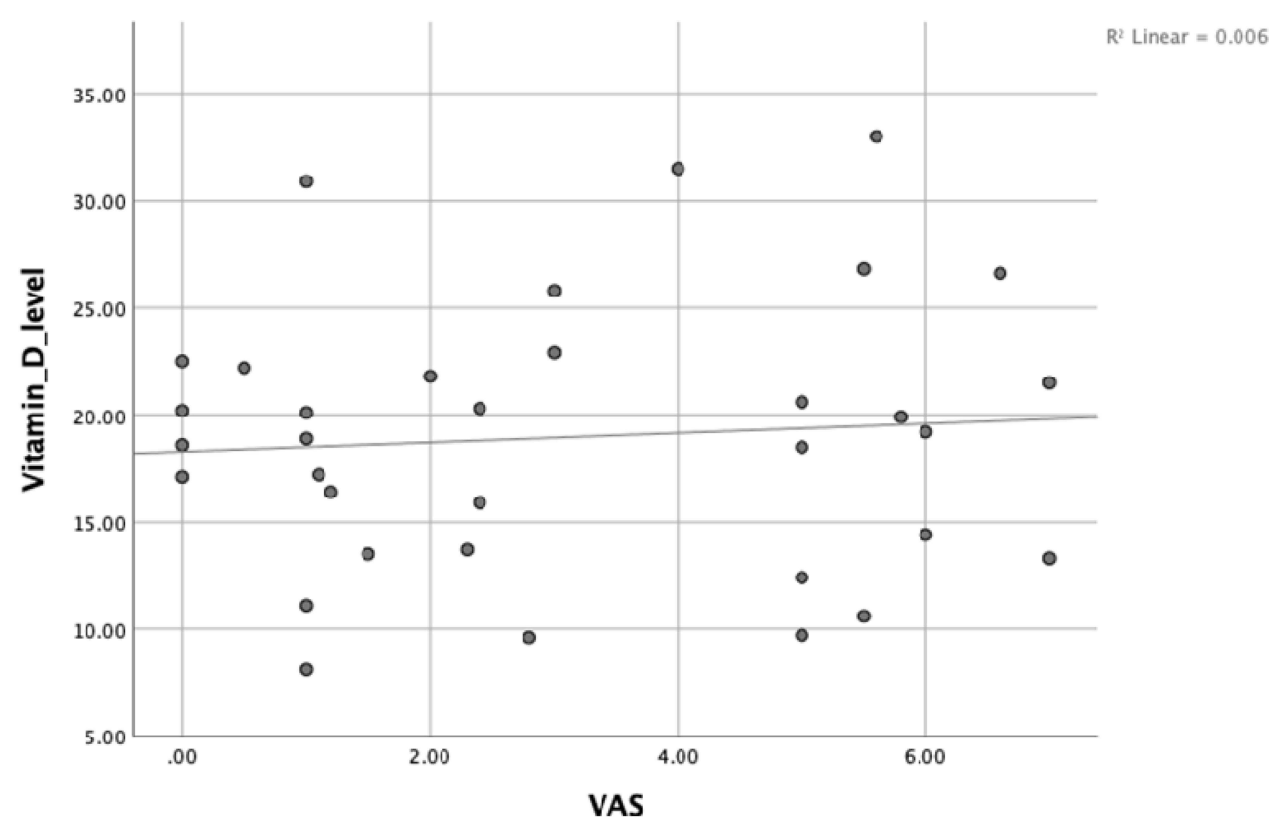

Figure 3 Correlation between vitamin D levels [serum $25(\mathrm{OH}) \mathrm{D}]$ and the VAS at week-8 in the control group.

a serum level of more than $30 \mathrm{ng} / \mathrm{mL}$ is necessary to optimize vitamin D's medical benefits. ${ }^{13,14}$ This study aimed to compare the pain impact and vitamin D levels after adding oral vitamin D 5000 IU to standard treatment in patients with diabetic neuropathy.

Adding oral vitamin D 5000 IU to standard treatment was demonstrated better in changes of VAS, burning pain, electric shocks pain, tingling, numbness scores, and vitamin D levels after eight weeks of treatment compared to standard treatment alone. A prospective observational study of 51 type-2 diabetic patients with neuropathic pain reported that three months of oral vitamin D3 supplementation improved visual analog scale scores significantly from 3.3 to $17.7^{7}$ Furthermore, in a placebo-controlled study involving 112 patients with type 2 diabetes who were randomly assigned to receive 50,000 IU of vitamin D once weekly for eight weeks, there was a significant increase in 25 $(\mathrm{OH}) \mathrm{D}$ and an improvement in the neuropathy symptom score. $^{2}$

Vitamin D supplementation is necessary for patients with peripheral neuropathy since it promotes the synthesis of neurotrophins and neurotransmitters. Nociceptive calcitonin gene associated peptide (CGRP)-positive neurons have a distinct vitamin $\mathrm{D}$ phenotype with hormonally controlled ligand and receptor levels, suggesting a mechanistic associa- tion between vitamin D and neuropathic pain. ${ }^{15}$ Vitamin $\mathrm{D}$ deficiency causes an increase in the number of axons expressing CGRP, and vitamin D receptor (VDR) expression is increased in growth cones in culture, suggesting that VDR-mediated rapid response signaling pathways control sprouting. ${ }^{16}$ Vitamin D supplementation also increases nerve growth factor (NGF), a protein needed for nerve growth and maintenance in the peripheral nervous system. ${ }^{17}$ Furthermore, vitamin D deficiency has been attributed to a lower pain tolerance, which improves when the deficiency is resolved. ${ }^{8}$

Vitamin D's pleiotropic benefit, which includes improved glycemic regulation, is becoming more widely known. Improvements in serum vitamin D levels have been related to lower HbAlc levels, reduced insulin resistance, and improvement in insulin sensitivity. Vitamin D is also unlikely to have any adverse implications. Thus, vitamin $\mathrm{D}$ not only relieves pain but also improves glycemic regulation. ${ }^{10,18-21}$ Not only is vitamin $\mathrm{D}$ beneficial for neuropathy in type 2 diabetes patients, the previous study has shown that vitamin D also improves neuropathy symptoms in type 1 diabetes patients. ${ }^{8}$

Our study has some limitations. Since this study was an open-label design, the possible effect of treatment details on outcomes should be considered. The unblinding nature of the 


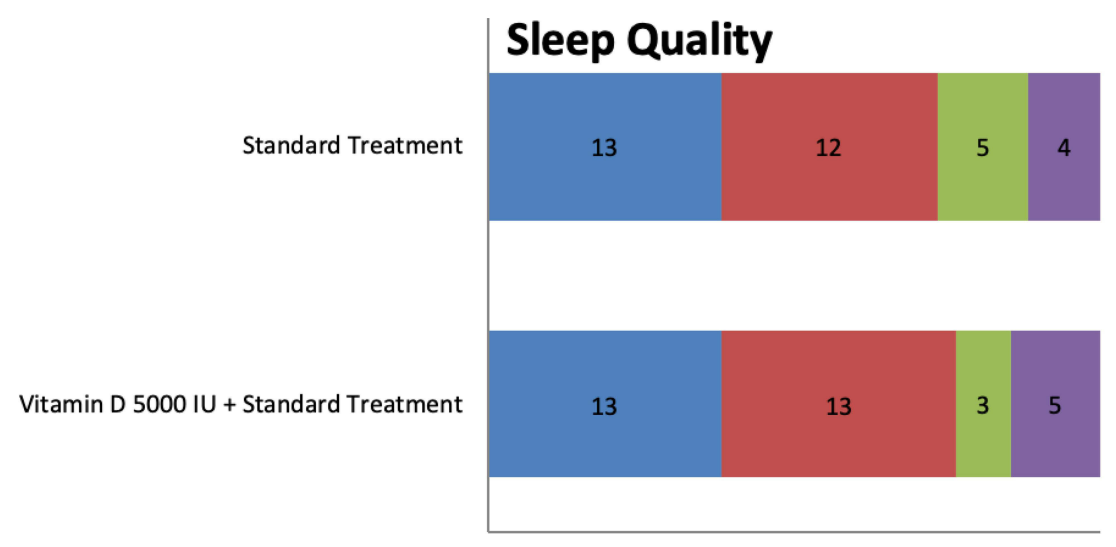

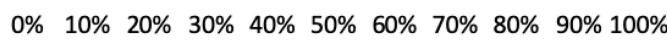
- Vastly improved Improved $\quad$ Slightly improved $\quad$ No improvement

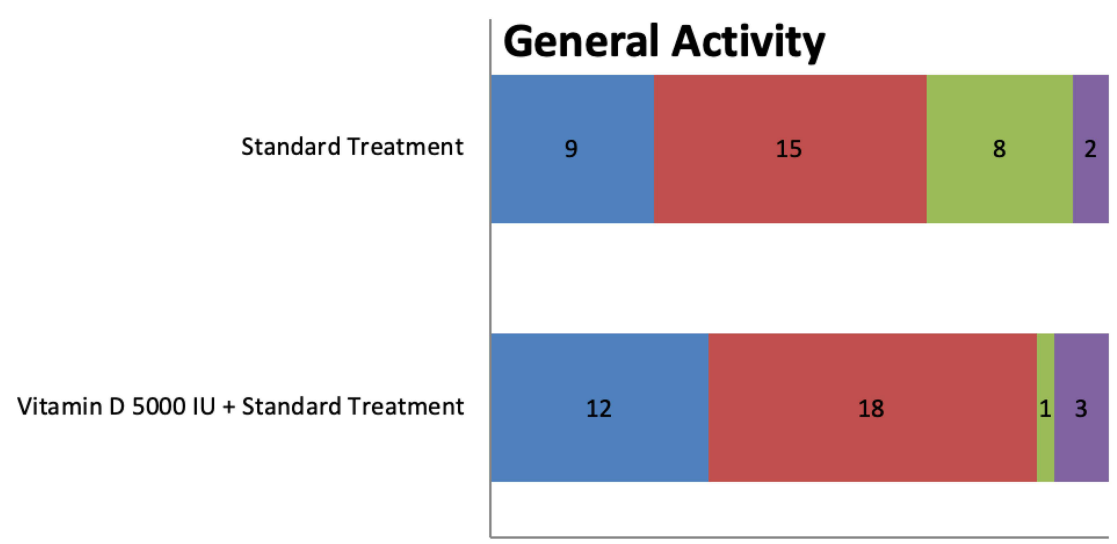

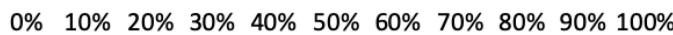

- Vastly improved IImproved $\quad$ Slightly improved $\quad$ No improvement

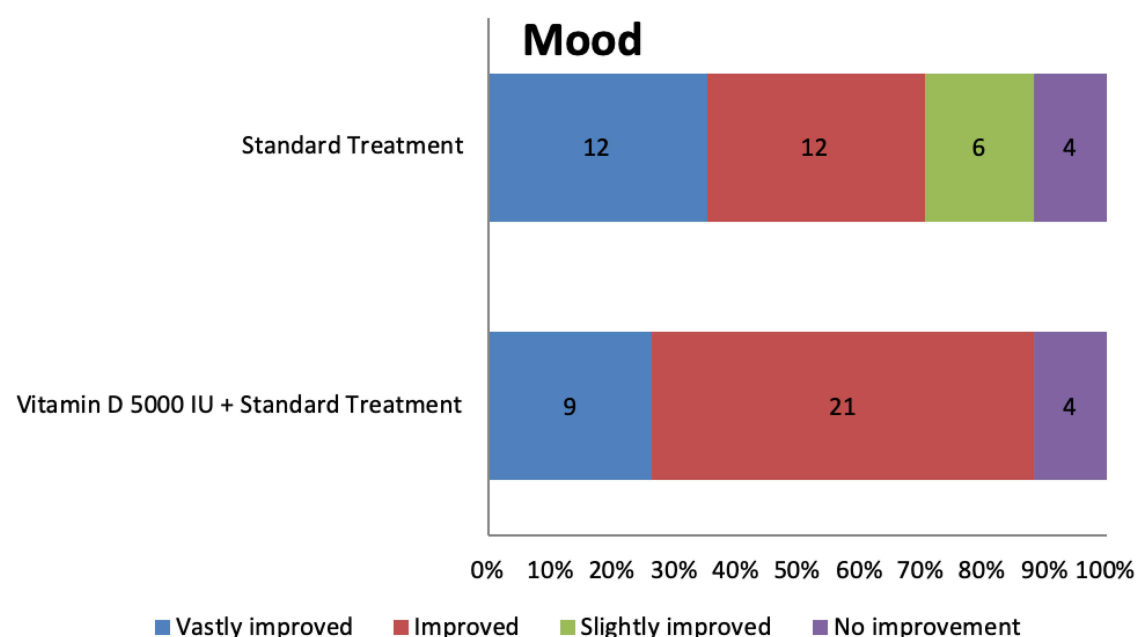

Figure 4 Distribution of sleep quality, general activity, and mood improvement at week 8 in the experimental and control groups. 
Table 3 Comparing the Improvement of Sleep Quality, General Activity, and Mood Between Both Groups at Week 8 (Visit 3 )

\begin{tabular}{|c|c|c|c|c|}
\hline & Vitamin D $5000 \mathrm{IU}+$ Standard Treatment $(n=34)$ & Standard Treatment $(n=34)$ & Total $(n=68)$ & p-value \\
\hline \multicolumn{5}{|l|}{ Sleep Quality } \\
\hline Vastly improved & $13(38.2 \%)$ & $13(38.2 \%)$ & $26(38.2 \%)$ & 0.885 \\
\hline Improved & $13(38.2 \%)$ & $12(35.3 \%)$ & $25(36.8 \%)$ & \\
\hline Slightly improved & $3(8.8 \%)$ & $5(14.7 \%)$ & $8(11.8 \%)$ & \\
\hline No improvement & $5(14.7 \%)$ & $4(11.8 \%)$ & $9(13.2 \%)$ & \\
\hline \multicolumn{5}{|l|}{ General Activity } \\
\hline Vastly improved & $12(35.3 \%)$ & $9(26.5 \%)$ & 21 (30.9\%) & 0.096 \\
\hline Improved & 18 (52.9\%) & $15(44.1 \%)$ & $33(48.5 \%)$ & \\
\hline Slightly improved & I (2.9\%) & $8(23.5 \%)$ & $9(13.2 \%)$ & \\
\hline No improvement & $3(8.8 \%)$ & $2(5.9 \%)$ & $5(7.4 \%)$ & \\
\hline \multicolumn{5}{|l|}{ Mood } \\
\hline Vastly improved & 9 (26.4\%) & 12 (35.3\%) & 21 (6I.8\%) & $0.031 *$ \\
\hline Improved & 21 (6I.8\%) & 12 (35.3\%) & 33 (48.5\%) & \\
\hline Slightly improved & $0(0 \%)$ & $6(17.6 \%)$ & $6(8.8 \%)$ & \\
\hline No improvement & 4 (II.8\%) & 4 (II.8\%) & 8 (II.8\%) & \\
\hline
\end{tabular}

Notes: Vastly improved: $>50 \%$ improvement on their score; Improved: 30-50\% improvement on their score; Slightly improved: 10-30\% improvement on their score; No improvement: $<10 \%$ improvement on their score; *p-value is statistically significant.

Table 4 Comparison of Vitamin D Levels [Serum 25(OH) D] Between the Experimental and Control Groups

\begin{tabular}{|c|l|l|l|}
\hline & $\begin{array}{l}\text { Vitamin D 5000 } \\
\text { IU + Standard } \\
\text { Treatment } \\
(\mathbf{n = 3 4 )}\end{array}$ & $\begin{array}{l}\text { Standard } \\
\text { Treatment } \\
(\mathbf{n}=34)\end{array}$ & p-value $^{\text {a }}$ \\
\hline Vitamin D levels (ng/mL) & $15.62 \pm 8.69$ & 0.905 \\
\hline Baseline & $15.87 \pm 8.50$ & $18.73 \pm 6.88$ & $<0.00 I^{*}$ \\
\hline Week 8 & $40.02 \pm 15.33$ & $+3.10 \pm 4.20$ & $<0.00 I^{*}$ \\
\hline $\begin{array}{l}\text { Changes } \\
\text { from baseline to } \\
\text { week 8 }\end{array}$ & $+24.14 \pm 13.68$ & & \\
\hline P-value & $<0.00 I^{\text {b }}$ & $<0.00 I^{*}$ & \\
\hline
\end{tabular}

Notes: Data are presented as mean \pm standard deviation (SD); ${ }^{\mathrm{a} C o m p a r i s o n}$ between the experimental and control group; ${ }^{\mathrm{b} C o m p a r i s o n}$ within-group under the same conditions; ${ }^{\mathrm{p}} \mathrm{p}$-value is statistically significant.

study may also impact the outcome. Moreover, the vitamin D dosage and potential dose adjustment were not analyzed and compared. Future studies with a double-blind design comparing various dosages and adjustment of vitamin
D supplementation are needed to achieve the best therapeutic options.

\section{Conclusion}

The addition of oral vitamin D 5000 IU to standard treatment significantly improves pain, mood and increases vitamin D levels more effectively than standard treatment alone in diabetic neuropathy. Our findings support the use of vitamin D supplements for the treatment of diabetic neuropathy patients.

\section{Vitamin D levels}

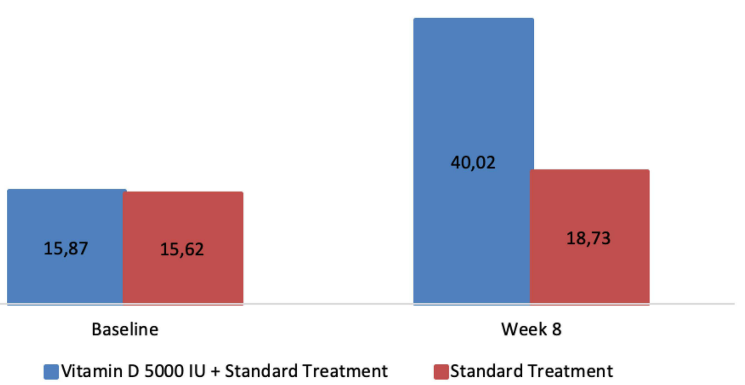

Figure 5 Change from baseline in mean vitamin $D$ levels [serum 25(OH) D], before and after the intervention between both groups (in $\mathrm{ng} / \mathrm{mL}$ ). 


\section{Data Sharing Statement}

The data supporting the findings of this study are available from the first author, Rizaldy Taslim Pinzon, on request Kindly contact drpinzon17@gmail.com for any queries.

\section{Funding}

The authors funded this study.

\section{Disclosure}

The authors declare no conflicts of interest.

\section{References}

1. Ghadiri-Anari A, Mozafari Z, Gholami S, et al. Does vitamin D supplementations improve peripheral diabetic neuropathy? A before-after clinical trial. Diabetes Metab Syndr. 2019;13(1):8 90-893. doi:10.1016/j.dsx.2018.12.014

2. Shehab D, Al-Jarallah K, Abdella N, Mojiminiyi OA, Al Mohamedy H. Prospective evaluation of the effect of short-term oral vitamin D supplementation on peripheral neuropathy in type 2 diabetes mellitus. Med Princ Pract. 2015;24(3):250-256. doi:10.1159/ 000375304

3. Chaychi L, Mackenzie T, Bilotta D, Lynch M, Cohen J, Comi R. Association of serum vitamin D level with diabetic polyneuropathy. Med Practise Rev Feb. 2011;2:11-15.

4. Shehab D, Al-Jarallah K, Mojiminiyi OA, Al Mohamedy H, Abdella NA. Does vitamin D deficiency play a role in peripheral neuropathy in type 2 diabetes? Diabet Med. 2012;29(1):43-49. doi:10.1111/j.1464-5491.2011.03510.x

5. Soderstrom LH, Johnson SP, Diaz VA, Mainous AG. Association between vitamin $\mathrm{D}$ and diabetic neuropathy in a nationally representative sample: results from 2001-2004 NHANES. Diabet Med. 2012;29 (1):50-55. doi:10.1111/j.1464-5491.2011.03379.x

6. Valensi P, Le Devehat C, Richard JL, et al. A multicenter, double-blind, safety study of QR-333 for the treatment of symptomatic diabetic peripheral neuropathy. A preliminary report. $J$ Diabetes Complications. 2005;19(5):247-253. doi:10.1016/j.jdiacomp.2005.05. 011

7. Lee P, Chen R. Vitamin D as an analgesic for patients with type 2 diabetes and neuropathic pain. Arch Intern Med. 2008;168 (7):771-772. doi:10.1001/archinte.168.7.771

8. Bell DS. Reversal of the symptoms of diabetic neuropathy through correction of vitamin D deficiency in a type 1 diabetic patient. Case Rep Endocrinol. 2012;2012:165056. doi:10.1155/2012/165056
9. Sadosky A, Schaefer C, Mann R, et al. Burden of illness associated with painful diabetic peripheral neuropathy among adults seeking treatment in the US: results from a retrospective chart review and cross-sectional survey. Diabetes Metab Syndr Obes. 2013;6:79-92. doi:10.2147/DMSO.S37415

10. Basit A, Basit KA, Fawwad A, et al. Vitamin D for the treatment of painful diabetic neuropathy. BMJ Open Diabetes Res Care. 2016;4 (1):e000148. doi:10.1136/bmjdrc-2015-000148

11. Rubin RR, Peyrot M. Quality of life and diabetes. Diabetes Metab Res Rev. 1999;15(3):205-218. doi:10.1002/(SICI)1520-7560(199905/ 06) $15: 3<205:: A I D-D M R R 29>3.0 . C O ; 2-O$

12. Alam U, Fawwad A, Shaheen F, et al. Improvement in neuropathy specific quality of life in patients with diabetes after vitamin d supplementation. J Diabetes Res. 2017:7928083. doi:10.1155/2017/ 7928083

13. Forouhi NG, Ye Z, Rickard AP, et al. Circulating 25-hydroxyvitamin $\mathrm{D}$ concentration and the risk of type 2 diabetes: results from the European Prospective Investigation into Cancer (EPIC)-Norfolk cohort and updated meta-analysis of prospective studies. Diabetologia. 2012;55(8):2173-2182. doi:10.1007/s00125-012-25 44-y

14. Holick MF, Chen TC. Vitamin D deficiency: a worldwide problem with health consequences. Am J Clin Nutr. 2008;87(4):1080S-1086S. doi:10.1093/ajen/87.4.1080S

15. Tague SE, Smith PG. Vitamin D receptor and enzyme expression in dorsal root ganglia of adult female rats: modulation by ovarian hormones. J Chem Neuroanat. 2011;41(1):1-12. doi:10.1016/j. jchemneu.2010.10.001

16. Tague SE, Clarke GL, Winter MK, McCarson KE, Wright DE, Smith PG. Vitamin D deficiency promotes skeletal muscle hypersensitivity and sensory hyperinnervation. J Neurosci. 2011;31(39): 13728-13738.

17. Carlson AN, Kenny AM. Is vitamin D insufficiency associated with peripheral neuropathy? Endocrinologist. 2007;17:319-325. doi:10. 1097/TEN.0b013e3181594284

18. Pittas AG, Lau J, Hu FB, Dawson-Hughes B. The role of vitamin $\mathrm{D}$ and calcium in type 2 diabetes. A systematic review and meta-analysis. J Clin Endocrinol Metab. 2007;92(6):2017-2029. doi:10.1210/jc.2007-0298

19. Dalgard C, Petersen MS, Weihe P, et al. Vitamin D status in relation to glucose metabolism and type 2 diabetes in septuagenarians. Diabetes Care. 2011;34:1284-1288. doi:10.2337/dc10-2084

20. Maddaloni E, Cavallari I, Napoli N, Conte C. Vitamin D and diabetes mellitus. Vitamin D in clinical medicine. Front Horm Res. 2018;50:161-176. doi:10.1159/000486083

21. Lips P, Eekhoff M, van Schoor N, et al. Vitamin D and type 2 diabetes. J Steroid Biochem Mol Biol. 2017;173:280-285. doi:10. 1016/j.jsbmb.2016.11.021
Journal of Pain Research

\section{Publish your work in this journal}

The Journal of Pain Research is an international, peer reviewed, open access, online journal that welcomes laboratory and clinical findings in the fields of pain research and the prevention and management of pain. Original research, reviews, symposium reports, hypothesis formation and commentaries are all considered for publication. The manuscript management system is completely online and includes a very quick and fair peer-review system, which is all easy to use. Visit http:// www.dovepress.com/testimonials.php to read real quotes from published authors.

\section{Dovepress}

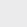

